CONF-970739--1

\title{
CFD ANALYSIS OF A LIQUID MERCURY TARGET FOR THE NATIONAL SPALLATION NEUTRON SOURCE
}

\author{
Mark W. Wendel \\ Computational Physics and Engineering Division \\ Moshe Siman Tov \\ Engineering Technology Division
}

Oak Ridge National Laboratory*

Oak Ridge, Tennessee 37831-6415

To be considered for presentation at ASME 1997 Fluids Engineering Division Summer Meeting July 22-26, 1997

Vancouver, British Columbia

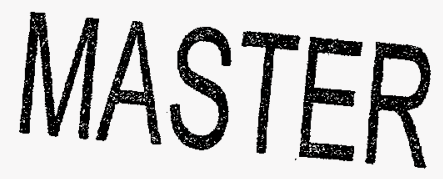

\footnotetext{
The submitted manuscript has been authored by a contractor of the U.S. Government under contract No. DEAC05-96OR22464. Accordingly, the U.S.

Government retains a nonexclusive, royalty-free license to publish or reproduce the published form of this contribution, or allow other to do so, for U.S. Government purposes."
}

* Managed by Lockheed Martin Energy Research Corp. for the U.S. Department of Energy under contract DE-AC05-96OR22464. 


\section{DISCLAIMER}

This report was prepared as an account of work sponsored by an agency of the United States Government. Neither the United States Government nor any agency thereof, nor any of their employees, make any warranty, express or implied, or assumes any legal liability or responsibility for the accuracy, completeness, or usefulness of any information, apparatus, product, or process disclosed, or represents that its use would not infringe privately owned rights. Reference herein to any specific commercial product, process, or service by trade name, trademark, manufacturer, or otherwise does not necessarily constitute or imply its endorsement, recommendation, or favoring by the United States Government or any agency thereof. The views and opinions of authors expressed herein do not necessarily state or reflect those of the United States Government or any agency thereof. 


\section{DISCLAMMER}

Portions of this document may be illegible in electronic image products. Images are produced from the best available original document. 


\title{
CFD ANALYSIS OF A LIQUID MERCURY TARGET FOR THE NATIONAL SPALLATION NEUTRON SOURCE
}

\begin{abstract}
Computational fluid dynamics (CFD) is being used to analyze the design of the National Spallation Neutron Source (NSNS) target. The target is subjected to the neutronic (internal) heat generation that results from the proton collisions with the mercury nuclei. The liquid mercury simuitaneously serves as the neutronic target medium, transports away the heat generated within itself, and cools the metallic target structure. Recirculation and stagnation zones within the target are of particular concern because of the likelihood that they will result in local hot spots. These zones exist because the most feasible target designs include a complete U-tum flow redirection. Although the primary concern is that the target is adequately cooled, the pressure drop from inlet to outlet must also be considered because pressure drop directly affects structural loading and required pumping power. Various design options have been considered in an effort to satisfy these design criteria. Significant improvements to the design have been recommended based on the results.

Detailed results are presented for the current target design including a comparison with published pressure-drop data. Comparisons are also made with forced convection heat transfer data for liquid mercury flow in circular tubes.
\end{abstract}

\section{NOMENCLATURE}

\begin{tabular}{clc} 
Symbol & Description & Units \\
\hline$a_{0}$ & height of center channel & $\mathrm{m}$ \\
$h$ & clearance between flow baffle and front of enclosure & $\mathrm{m}$ \\
$h_{0}$ & offset of flow guide outer edge from tip of flow baffle & $\mathrm{m}$ \\
$p$ & pressure & $\mathrm{Pa}$ \\
$T$ & temperature & $\mathrm{K}$ \\
$w_{0}$ & velocity in the center channel & $\mathrm{m} / \mathrm{s}$ \\
$x$ & horizontal space coordinate parallel to proton beam & $\mathrm{m}$ \\
$y$ & horizontal coordinate perpendicular to proton beam & $\mathrm{m}$ \\
$y^{+}$ & wall coordinate in law-of-the-wall boundary condition (dimensionless) & - \\
$\zeta$ & hydraulic loss coefficient (dimensionless) & - \\
$\rho$ & density & $\mathrm{kg} / \mathrm{m}^{3}$
\end{tabular}

\section{INTRODUCTION}

The National Spallation Neutron Source (NSNS) is a high-power accelerator-based pulsed spallation source being designed by a multilaboratory team led by Oak Ridge National Laboratory (ORNL) to achieve high fluxes of neutrons for scientific experiments [Siman-Tov, Wendel, and Haines (1997)]. The NSNS is projected to have a 1-MW proton beam that is upgradable to $5 \mathrm{MW}$ with a beam cross-section of $7 \times 20 \mathrm{~cm}$. About $60 \%$ of the beam power (1-5 MW, $17-83 \mathrm{~kJ} /$ pulse in $0.5 \mu \mathrm{s}$ at $60 \mathrm{cps})$ is deposited in the liquid metal (mercury) target having the dimensions of $65 \times 40 \times 10 \mathrm{~cm}$ (about $20 \mathrm{~L}$ ). Figure 1 shows the design schematic 
upon which the present analysis is based The target is subjected to the neutronic (internal) heat generation that results from the proton collisions with the target nuclei. Peak instantaneous power density is as high as $1 \times 10^{7}$ and $5 \times 10^{7} \mathrm{MW} / \mathrm{m}^{3}$, for the $1-$ and $5-\mathrm{MW}$ beams respectively. The peak pulse rate of temperature rise is $5.8 \times 10^{6} \mathrm{~K} / \mathrm{s}$ (for $1-\mathrm{MW}$ beam), whereas the total pulse temperature rise is less than $3 \mathrm{~K}$. The distribution of power deposition within the mercury has a peak-to-average ratio of 3.5 axially and 2.0 radially. The target stainless steel has a similar spatial distribution of heat. In addition to thermal shock and materials compatibility, key feasibility issues for the target are related to its thermal-hydraulic performance.

The liquid mercury simultaneously serves as a the neutronic target medium, transports away the heat deposited within itself, and cools the metallic target structure. The proton beam (see Fig. 1) is parallel to the primary direction of flow. The beam first passes through the stainless steel window on the front of the target which is provided with supplemental exterior cooling by an attached cooling jacket that wraps around the target lengthwise. The transverse extent of the cooling jacket is limited to the width necessary to contain the proton beam path. The array of short, right circular cylinders on the top of the target (see Fig. 1) are structural supports for the thin-walled cooling jacket. Recirculation and stagnation zones within the target are of particular concern because of the likelihood that they will result in local hot spots. Recirculation and stagnation occur in the most feasible target designs, which include a U-turn flow redirection. Although the primary concern is that the target is adequately cooled, the target pressure drop must also be considered because it directly affects structural loading and required pumping power.

Computational fluid dynamics (CFD) is being used to assist in the design of the NSNS target by providing flow visualization and quantifying critical parameters. The simplest approach to the fluid dynamics analysis is to time-average the problem. Of course the flow is already time-averaged with regard to turbulent fluctuations about a mean flow. This additional level of averaging is accomplished by spreading the pulse energy evenly throughout the entire period of $0.01667 \mathrm{~s}$ (corresponding to a pulse frequency of $60 \mathrm{cps}$ ), allowing the simulation to be performed as a steady state. The steady-state solution should provide a reasonable estimate for the overall flow pattern and temperature distribution within the target enclosure. Also of concern, however, are transient effects which occur on the microsecond time scale and which impact the target

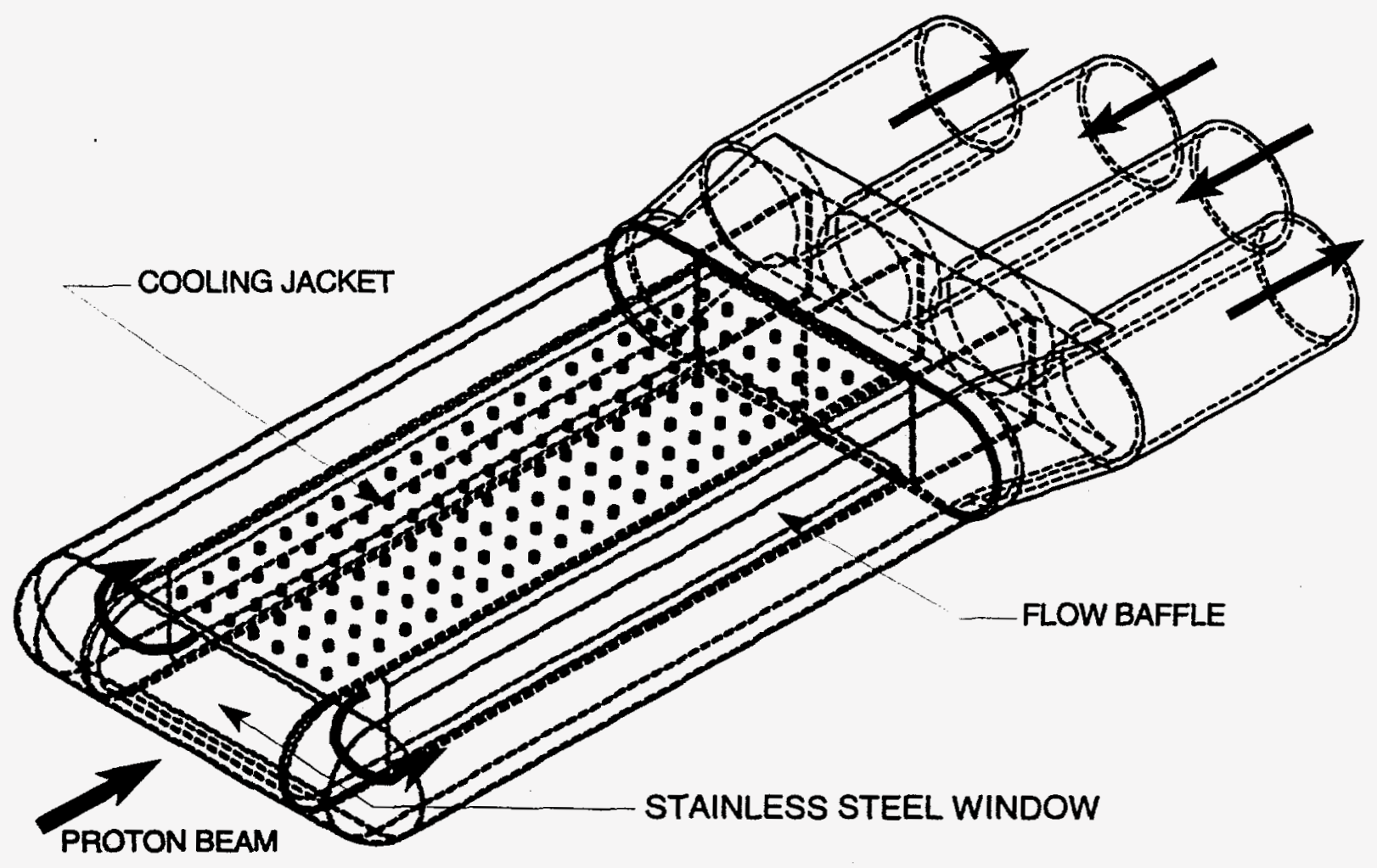

Fig 1. Design schematic showing the NSNS stainless steel target enclosure to be used for liquid mercury containment. 
performance. These effects include small spatial and temporal variations in the flow field and pressure shock waves induceed by rapid thermal expansion (density decrease) of the heated liquid. A separate study is underway usimg CTH [McGlaun, Thompson, Kmetyk, and Elrick (July 1990)], a code designed to model large deformations and strong shock wave physics, to quantify the shock wave amplitudes including fluid/structure interaction.

\section{DESCRIPTION OF THE INPUT MODEL}

The greneral-purpose CFD code CFX 4.1', which uses a finite-volume, pressure-correction method, is being used to simulate the incompressible, two-dimensional temperature and velocity distribution in the current concept of the liquid mercury target. To date, the simulations have all been two-dimensional because of the significantly reduced level of effort for model development and the ease of modification as the design evolves. It is assumed that the geometrical approximations necessary in formulating a two-dimensional model are not severe : enough such as to alter the primary characteristics of the flow. The computational domain for the current tanget design is shown in Fig. 2. Because of symmetry in the geometry, only one-half of the target was simulateri. The two-dimensional geometry is simply the centerline horizontal cross-section. This approximatiom neglects the curvature and narrowing of the outer semicircular channels near the periphery. However, the correct (within 3\%) cross-sectional flow area was applied to both channels by specifying a channel deptr of $0.0823 \mathrm{~m}$. Hence, the average flow velocity computed is within $3 \%$ of the actual value in both the central rectangular and the peripheral semicircular channels. Straight $1-m$ entrance and exit lengths are included : $m$ the model, but they are not shown in Fig. 2.

The model includes solid conducting regions that represent the stainless steel target walls and internal baffle. Heat geeneration is modeled in both of these regions. A renormalization-group isotropic, two-equation turbulence model provided by CFX is used in combination with the standard law-of-the-wall boundary condition for : rmposing wall heat fluxes in the energy equation and shear stress in the momentum equations. The boundary conditions include no-slip at the walls and specified pressure at the inlet and outlet boundaries. In some simusations a specified inlet velocity has been used with a continuitive (zero streamwise gradients) outlet conditicon. There are no significant differences in the steady-state simulation results using either of these two types of imiet/outlet boundary conditions. The density was assumed to be constant, but the viscosity and thermal concusetivity were allowed to vary with temperature. The temperature variation of the viscosity was included only for its impact in the law-of-the-wall formulation (outside the boundary layer, the eddy viscosity dominates); mowever, the variation had very little significance in the results. With a liquid metal such as mercury, the semperature gradient (and corresponding property variation) near the wall is much less severe because of high thermal conductivity.

The aiscretization used for the current design includes 18,212 computational cells and is shown in Fig. 3. Compnutational cell dimensions vary from $0.001 \mathrm{~m}$ near the tip of the flow baffle up to $0.100 \mathrm{~m}$ in the streamwise dirrection near the inlet-outlet plane. The cooling jacket is not included in the model. Its effect is accounted for through the use of a specified heat transfer coefficient and heat-sink temperature along the appropriate b:oundary. The variable heat generation within the target is added to the model using CFX usersupplied subroutines.

' CFX is developed by Computational Fluid Dynamics Services, part of AEA Technology, Harwell Lamoratories, Oxfordshire, United Kingdom. 


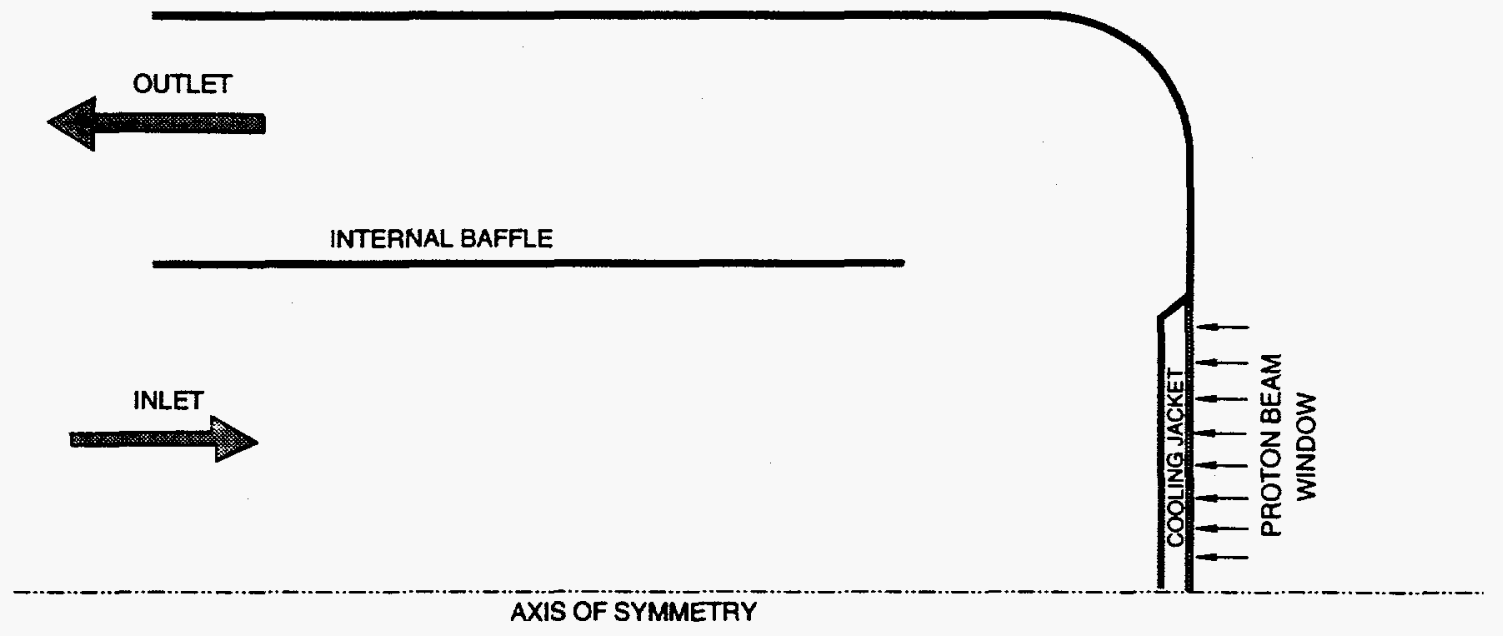

Fig 2. Computational flow domain for two-dimensional target model based on horizontal crosssection at vertical midplane..

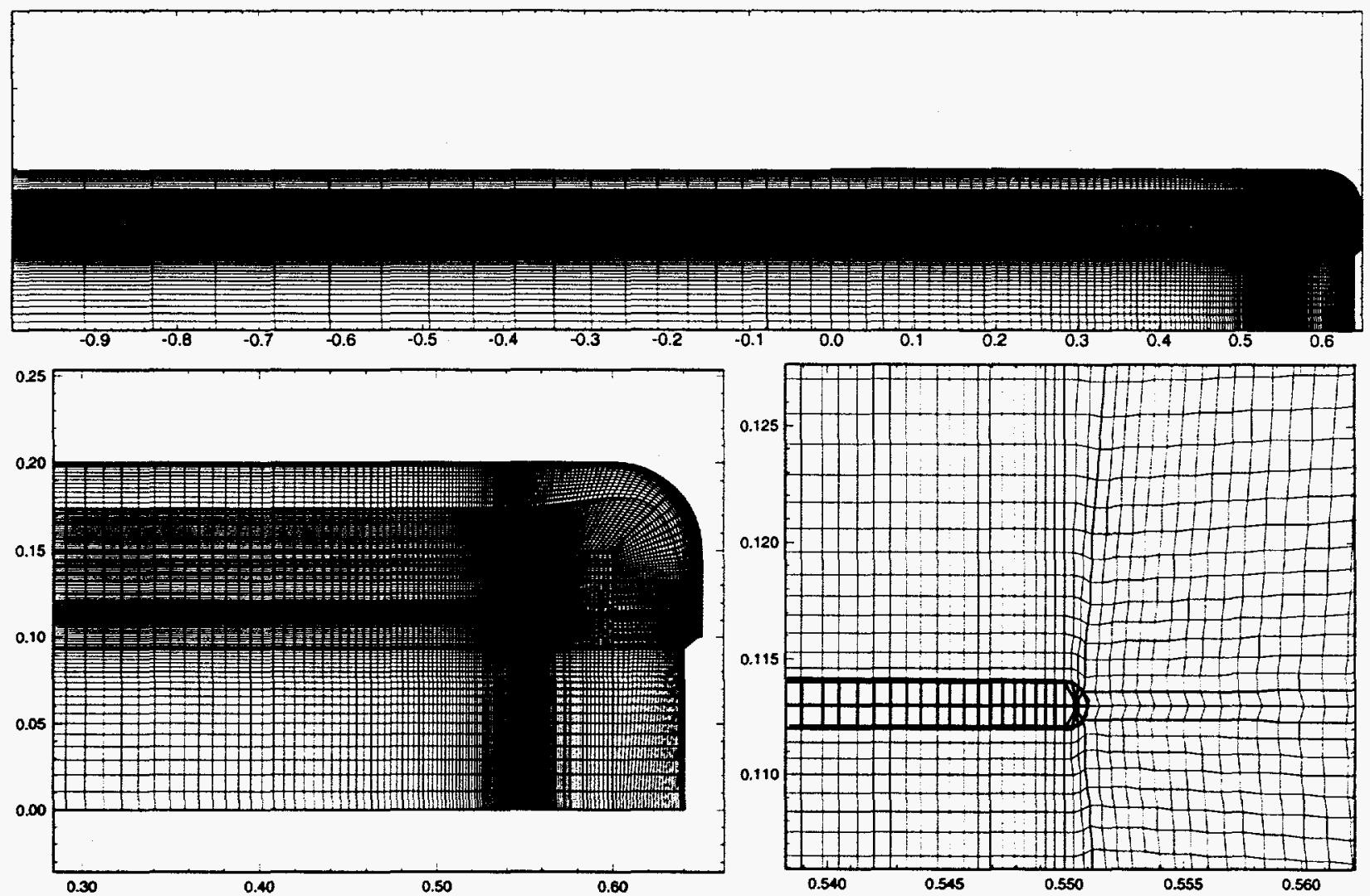

Fig 3. Discretization at three zoom levels for two-dimensional CFD model of Fig. 1 target design. 


\section{SIMULATION RESULTS}

Four simulations were performed in a progression moving toward a more efficient target design. The first two simulations use the Fig. 1 design to determine the best flow direction. The last two simulations assess possible design changes to improve the target performance. The mercury flow in the Fig. 1 target design can enter through the center pipes or through the side pipes. In this paper, flow entering the target through the rectangular (center) channel will be referred to as "center flow inlet," and the flow entering the target through the side semicircular channels will be referred to as "side flow inlet." All simulations assumed an inlet temperature of $353 \mathrm{~K}$ and total heat loading of $0.6 \mathrm{MW}$, corresponding to the 1-MW proton beam. The heat generation distribution is based on neutronics calculations performed for an earlier design. Heat is apportioned to constant-source rectangular regions with variation in both the axial and transverse directions, as shown in Fig. 4. The mass flow rate was assumed to be $140 \mathrm{~kg} / \mathrm{s}$, corresponding to an average center-section velocity of $0.567 \mathrm{~m} / \mathrm{s}$ and an average peripheral velocity of $0.756 \mathrm{~m} / \mathrm{s}$. Case 1 assumes a side flow inlet with the unmodified Fig. 1 design. Case 2 assumes a center flow inlet with the unmodified Fig. 1 design. Case 3 is the same as case 2 except that the cooling jacket has been widened. And, case 4 is the same as case 3 except for the addition of a semi-circular flow guide.

Heat Generation Rates $\left(W / \mathrm{cm}^{3}\right)$ in Liquid Mercury

Total Mercury Heat $=0.6 \mathrm{MW}$

\begin{tabular}{|c|c|c|c|c|c|}
\hline \multicolumn{6}{|c|}{0} \\
\hline 1.01 & 3.57 & 8.33 & 15.2 & 24.7 & 20.7 \\
\hline 2.01 & 9.12 & 26.4 & 56.9 & 117.5 & 127.2 \\
\hline
\end{tabular}

Fig 4. Heat generation from neutronics calculation adapted for current design heat load distribution.

Table 1 shows the resulting pressure drop, maximum speed, and maximum temperatures in both the mercury and stainless steel for each of the four simulations. Steady-state convergence from a zero initial condition required a few hours of CPU time on an IBM RS6000 Model 580 Workstation. A level of convergence was obtained such that the cumulative mass conservation error was less than $0.06 \%$ of the total target mass flow rate. The CFX advanced multigrid (AMG), linear solver greatly enhanced the rate of convergence.

The first simulation assumed the geometry as shown in Fig. 1 with side flow inlet, i.e. flow entering the target through the side channels and exiting down the center. The resulting flow pattern shows a large recirculation zone downstream of the flow baffle around which the liquid mercury makes the U-turn (Fig. 5). This large zone obstructs about one-half of the cross-sectional area in the central rectangular channel. Two smaller stagnation zones are also predicted in the corner of the target volume and near the stagnation point on the center line. The recirculating flow causes a relatively high pressure drop $(9.2 \mathrm{kPa})$ through the target in addition to elevating the local temperatures because of the high local residence time of the fluid. The problem is compounded because the location of the large recirculation zone lies directly in the beam path. 
Table 1. Key results for four simulated cases.

\begin{tabular}{c|l|c|c|c|c}
\hline Case & \multicolumn{1}{|c|}{ Description } & $\begin{array}{c}\text { Irreversible } \\
\text { Pressure Loss } \\
(\mathrm{Pa})\end{array}$ & $\begin{array}{c}\text { Maximum } \\
\text { Fluid Speed } \\
(\mathrm{m} / \mathrm{s})\end{array}$ & $\begin{array}{c}\text { Maximum Fluid } \\
\text { Temperature } \\
(\mathrm{K})\end{array}$ & $\begin{array}{c}\text { Maximum Stainless } \\
\text { Steel Temperature } \\
(\mathrm{K})\end{array}$ \\
\hline \hline 1 & Side flow inlet & 9222 & 1.73 & 465 & 443 \\
\hline 2 & Center flow inlet & 7962 & 1.78 & 445 & 445 \\
\hline 3 & $\begin{array}{l}\text { Center flow inlet with } \\
\text { extended jacket }\end{array}$ & 8029 & 1.79 & 430 & 430 \\
\hline 4 & $\begin{array}{l}\text { Center flow inlet } \\
\text { with extended jacket } \\
\text { and flow guide }\end{array}$ & 1768 & 1.53 & 420 & 424 \\
\hline
\end{tabular}

\section{STREAMLINES}

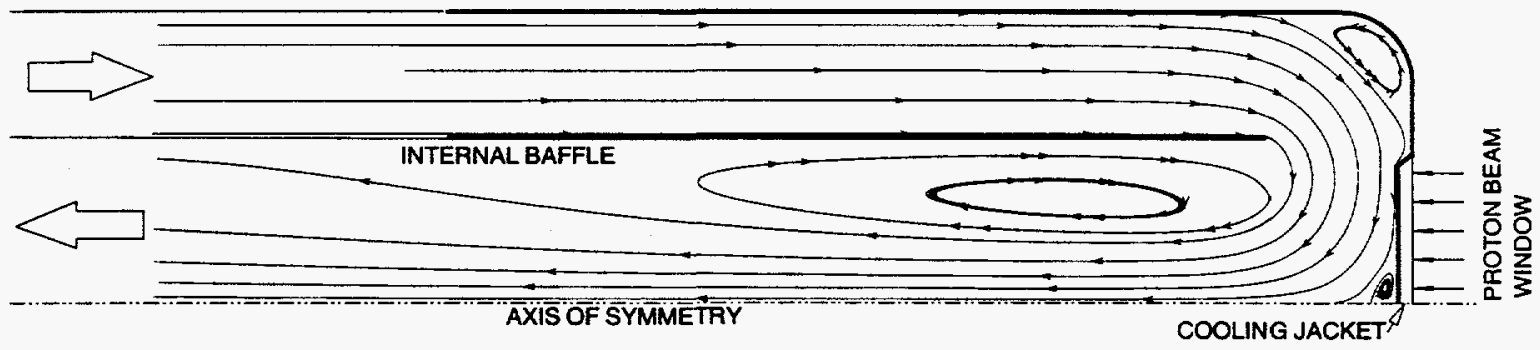

ISOTHERMS (K)

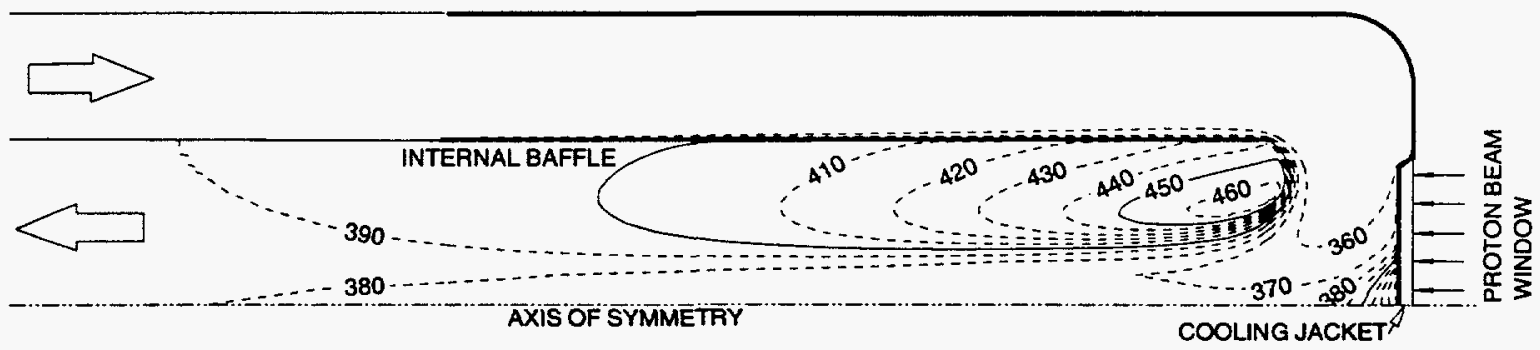

Fig 5. Results from the first simulation assuming baseline design and side flow inlet.

With center flow inlet, the recirculation zones moved outside of the beam path, as shown by the results in Fig. 6. The peak mercury temperatures are significantly lower because the recirculation zone is in a location with lower neutronic heating. A second advantage to using the center flow direction is that the pressure drop is predicted to be lower by $14 \%$. Figure 6 shows that a substantial recirculation zone exists downstream of (near the corner of) the cooling jacket. The reduced flow in the corner next to the jacket is close to a zone of high heat generation (in the beam path), such that the temperatures in the stainless steel wall are elevated near 


\section{STREAMLINES}

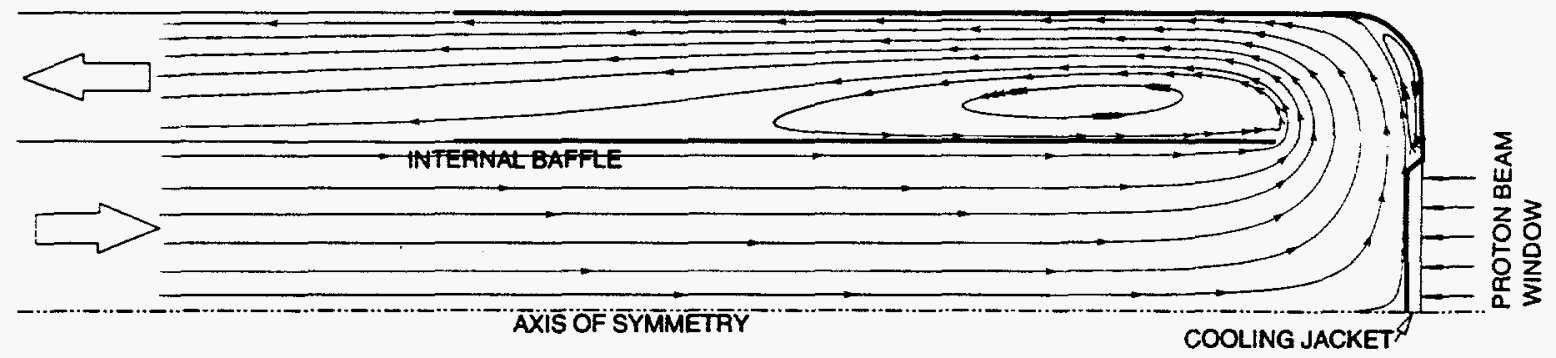

ISOTHERMS (K)

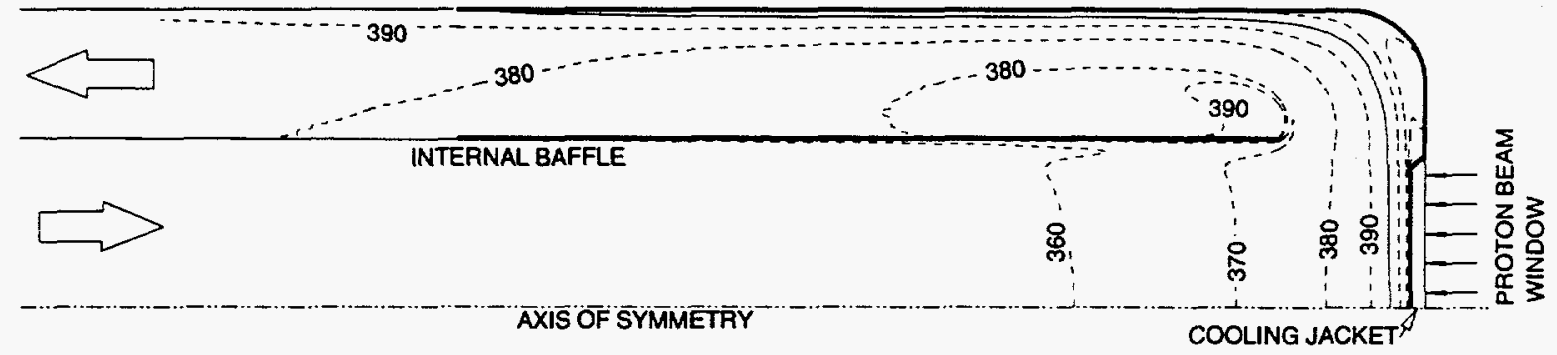

Fig 6. Computed results from second simulation using baseline design with center flow inlet.

the corner, as was shown in Table 1.

For the third simulation, the cooling jacket was extended in the transverse direction so that the corner was well outside the beam path. As shown in Table 1, this modification to the design resulted in dropping the mercury and stainless steel temperatures by $15 \mathrm{~K}$.

To reduce recirculation zones and the pressure drop in the target, the addition of an internal flow guide was investigated. The thin-walled $U$-shaped flow guide reenforces the turn and reduces separation of stream lines behind the flow baffle. Results shown in Fig. 7 and Table 1 indicate a much reduced pressure drop and an additional $10-\mathrm{K}$ reduction in the maximum fluid temperature. This reduction in temperature is brought on by a change in the flow pattern that supplies more flow to the corner of the cooling jacket. The recirculation zone behind the flow baffle has been much reduced. 


\section{STREAMLINES}

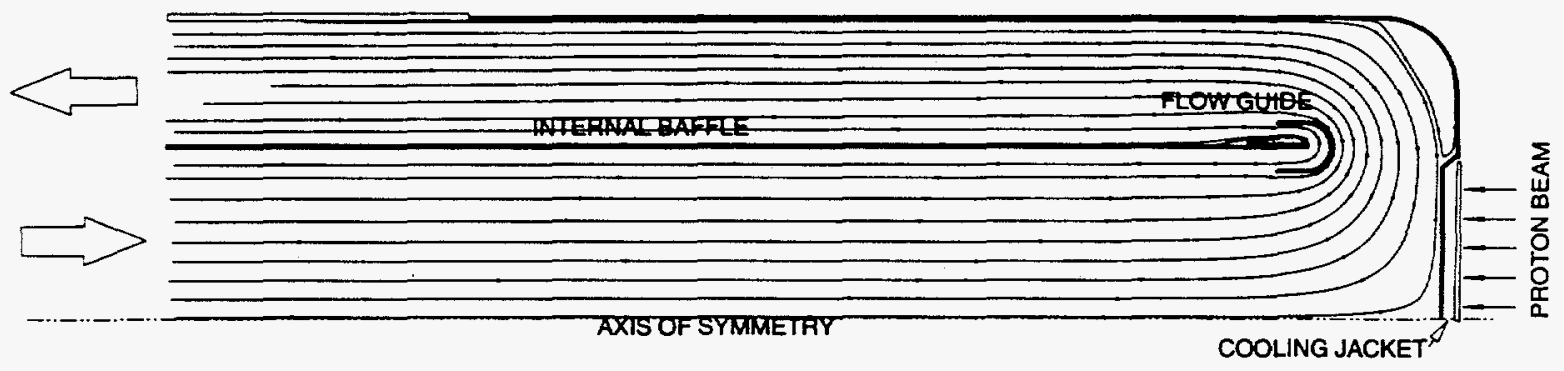

ISOTHERMS (K)

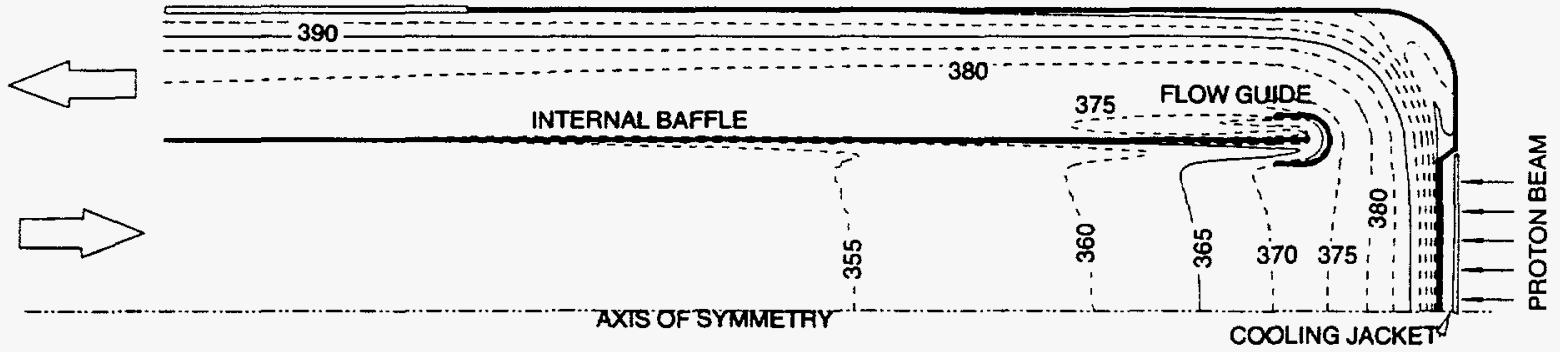

Fig 7. Results from the fourth simulation with center flow inlet and a flow guide installed.

\section{MODEL EVALUATION}

\section{Numerical Uncertainty}

To investigate the sensitivity of the solution to the coarseness of the grid, a more resolved discretization of the computational flow domain was created having 72,848 computational cells. The resolution near the wall was not doubled because the $y^{+}$values were already between 10 and 100 , well within the logarithmic overlap layer. Hence, the additional nodes allowed for more resolution away from the walls, which is particularly advantageous in the areas of recirculation.

The solution to case 2 (flow down the center with Fig. 1 design) was obtained on the finer mesh. This larger problem required 72 CPU-h (IBM 580 Workstation) for 9000 iterations to obtain steady state convergence. The results showed a total pressure drop of $7779 \mathrm{~Pa}(2.3 \%$ lower than the coarser-mesh simulation produced). The maximum speed in the side channel calculated with the fine mesh was $1.77 \mathrm{~m} / \mathrm{s}$ ( $0.6 \%$ lower). The maximum liquid temperature in the recirculation zone behind the flow baffle was unchanged at $394 \mathrm{~K}$, and the maximum mercury temperature overall was $446 \mathrm{~K}$ (only $1 \mathrm{~K}$ higher than the original result). Figure 8 shows a comparison of the stream lines for the two discretizations. This comparison indicates that the original discretization is adequate for predicting the two-dimensional flow field. 

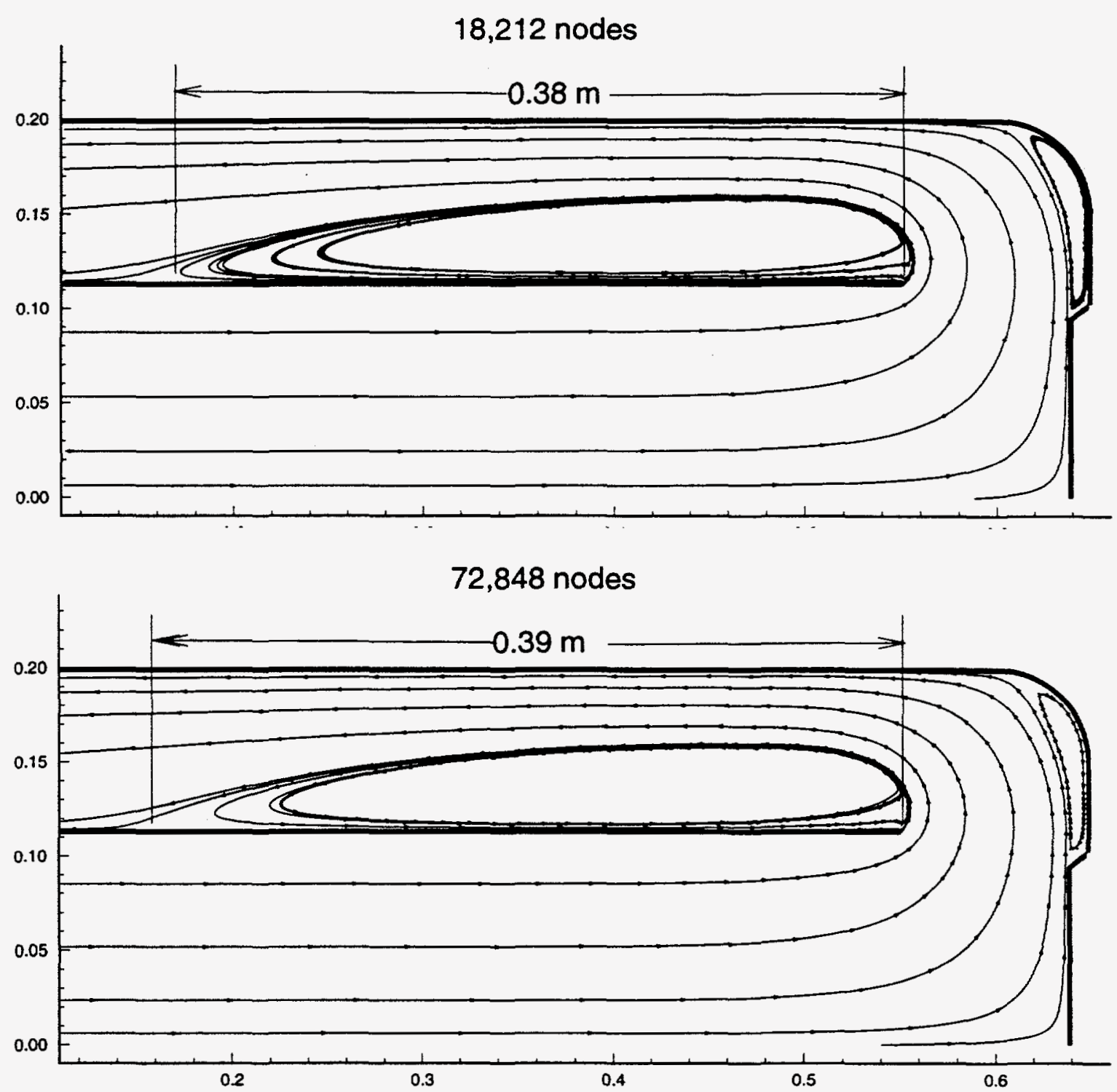

Fig 8. Streamlines showing similarity of recirculation pattern and reattachment length after mesh refinement.

\section{Physical Comparisons}

The wall heat transfer and shear stress boundary conditions are particularly important to the key results of the target simulations. For this reason, two comparisons with available data were performed. The first, is an assessment of the capability of the CFX code to accurately predict forced convective turbulent heat transfer with liquid mercury over a range of Peclet numbers.

Experimental data and theoretical correlations are available [Lubarsky and Kaufman (March 1995)]for 
turbulent, forced-convection heat transfer for liquid metal flowing in a tube with uniform wall heat flux. A CFX model was assembled for an axisymmetric circular pipe with a diameter of $0.01 \mathrm{~m}$ and a length of 0.50 $\mathrm{m}$. A CFX solution for the Nusselt number was compared with the experimental and theoretical results. Figure 9 shows the comparison over a range of Peclet numbers. The computed results are 5-25\% higher than the Lyon-Martinelli theoretical correlation [Lyon (April 1949)]. At a Peclet number of 12,000, corresponding to the actual target flow and temperature difference, the computed Nusselt number is only $5 \%$ higher than the theoretical prediction. There is close agreement between the CFX results and the theory despite the fact that both overpredict the measured Nusselt numbers. This is an expected result, because the experiments include effects not accounted for in the governing equations of mass, momentum, and energy conservation on which CFX is based (e.g. impurities in the liquid metal, nonuniform wall effects, and the well-known non-wetting characteristics of mercury.)

The second check on the computed results involves the calculation of the total pressure drop based on empirically derived loss coefficients. Idelchik (1994) provides practical values for a "symmetrical $180^{\circ}$ turn of the flow. . . in a plane channel." Figures 10 and 11 show the configuration referred to by Idelchik. These figures have some differences from the target configuration: the water-jacket indentation in the target, the ratio of the flow areas, and the radius of curvature at the corner of the outside wall. The flow guide appears to be off-center, and some dimensions are not given by Idelchik. The hand-calculated losses are based on the dimensions, as shown in Fig. 12.

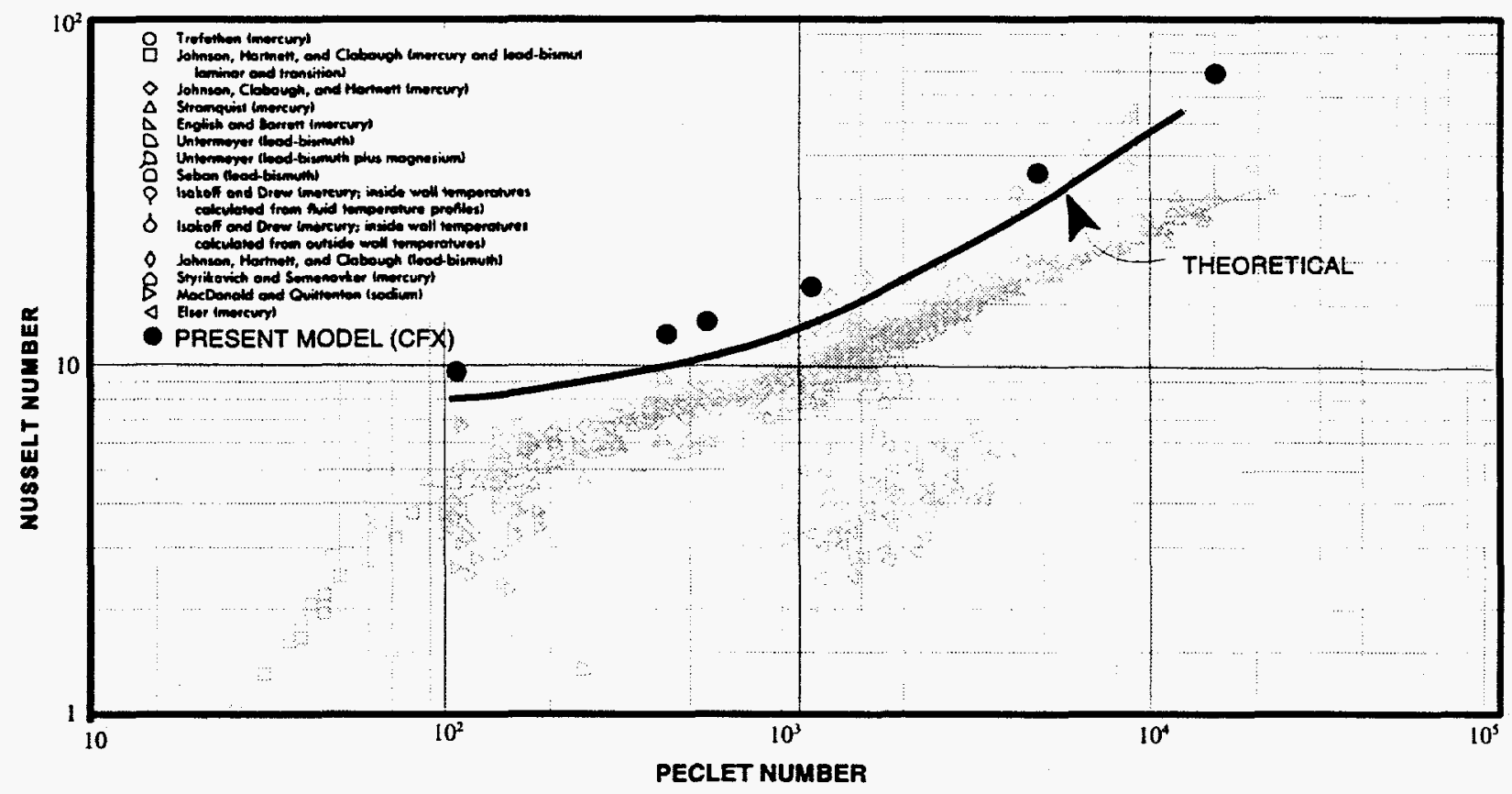

Fig 9. Comparison of CFX-computed heat transfer with theoretical and experimental results for forced convection of liquid metals in a tube with uniform wall heating. (Revised from: NACA-TN3336, March 1955.) 


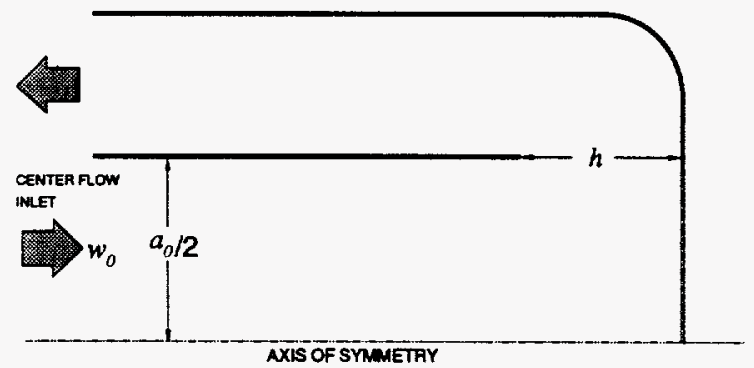

Fig. 10. Handbook loss coefficient geometrical configuration for symmetric planar channel U-turn.

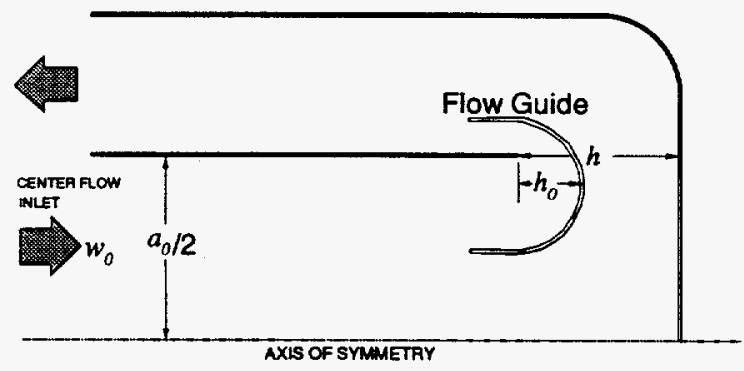

Fig. 11. Geometrical configuration for handbook loss coefficient with flow guide.

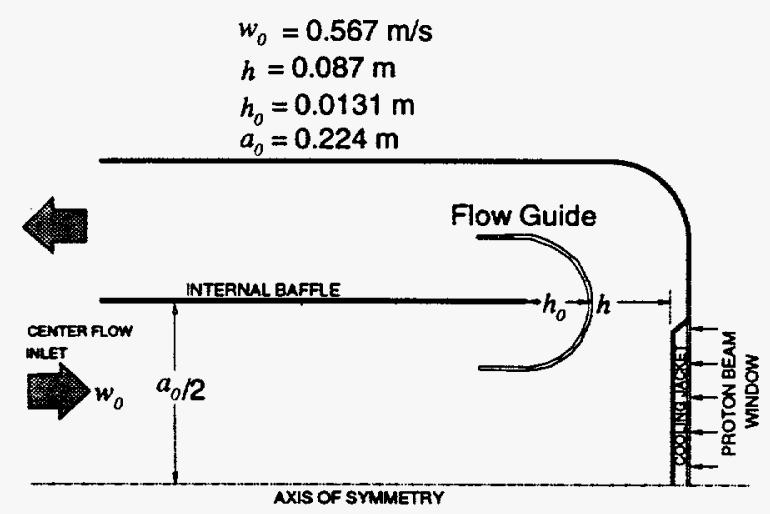

Fig. 12. Target dimensions with handbook parameters indicated. 
Using the parameters in Fig. $12\left(0.388<h / a_{0}<0.438\right)$ Idelchik indicates the loss coefficient, $\zeta$, given in Table 3. The two values shown correspond to $h$ with and without consideration of the cooling jacket. The total irreversible pressure loss, $\Delta p$, is found by evaluating the expression

$$
\Delta p=\frac{\zeta}{2} \rho w_{0}^{2},
$$

where the density, $\rho$, is $13,370 \mathrm{~kg} / \mathrm{m}^{3}$, and the velocity in the central channel, $w_{0}$, is $0.567 \mathrm{~m} / \mathrm{s}$.

Table 3. Comparison of computed and hand-calculated irreversible pressure loss for $180^{\circ}$ symmetric tum in a planar channel.

\begin{tabular}{l|c|c|c|c}
\hline Flow Direction & With Flow Guide? & $\zeta$ & $\begin{array}{c}\text { Idelchik } \Delta p \\
(\mathrm{~Pa})\end{array}$ & $\begin{array}{c}\text { CFX-Computed } \Delta p \\
(\mathrm{~Pa})\end{array}$ \\
\hline \hline Center & NO & $4.7-5.4$ & $10,100-11,605$ & 7962 \\
\hline Side & NO & $4.2-4.7$ & $9026-10,101$ & 9222 \\
\hline Center & YES & $1.3-1.5$ & $2792-3224$ & 1768 \\
\hline
\end{tabular}

The CFX results consistently underpredict the pressure drop calculated using the empirical loss coefficients. Part of this discrepancy may be attributed to three-dimensional effects that are not modeled. The most likely reason for the difference is uncertainty in the turbulence model.

\section{CONCLUSIONS}

Two-dimensional computational results from the CFX model for the spallation neutron source have been used to characterize the flow field in four alternate configurations. Recirculation zones and "hot spots" were identified, and possible improvements were investigated.

Results indicate very large regions of recirculation downstream of the flow-baffle separator plate no matter at which direction the flow is oriented. If the flow inlet to the target is down the center, then the recirculation zone lies outside the proton beam path and, hence, in a region with less heat generation. At this lower heat generation rate, the higher residence time for the liquid mercury in the recirculation is less of a factor than when the recirculation zone lay in the beam path. The maximum temperature in the recirculation zone is no longer the limiting hot spot. Two design improvements have been suggested for consideration: (1) transverse extension of the cooling jacket to push the comer further away from the beam path and (2) addition of a flow guide to reduce the target pressure drop by shrinking the size of the recirculation zone.

Evaluation of the model was performed to assess both numerical and physical accuracy. The numerical uncertainty resulting from the finite volume discretization was investigated by repeating one of the cases with a refined mesh (having four times the number of nodes.) The computed flow field was shown to be insensitive to the grid refinement, hence the solution on the original mesh represents an accurate solution of the difference equations.

Comparisons of CFX results with relevant experimental data and theory have been performed. At the Peclet number which characterizes the target flow for 1-MW beam power, the CFX program produced grid- 
independent results within 5-25\% of the published theoretical values with better accuracy at the Peclet number representative of $1 \mathrm{MW}$ target operation. However, this comparison was performed on a simple tube geometry, whereas the target geometry is a much more complicated flow path. When compared with published experimental form loss coefficients, the pressure drop was consistently underpredicted by CFX by as much as $30 \%$ without the flow guide, and $50 \%$ with the flow guide, although some small differences between experimental and computational geometry exist.

In the future, the CFX model will be expanded to include the three-dimensional geometry, nonwetting effects on mercury heat transfer and pressure drop, potential for cavitation around corners, and local transients resulting from the pulsed nature of the energy deposition.

\section{REFERENCES}

Idelchik, I. E., 1994. Handbook of Hydraulic Resistance, 3rd ed., CRC Press, Inc., Boca Raton, Florida, pp 353-356.

Lubarsky, B., and Kaufman, S. J., March 1955. Review of Experimental Investigations of Liquid-Metal Heat Transfer, NACA-TN-3336, Lewis Flight Propulsion Laboratory.

Lyon, R. N., April 1949. Forced Convection Heat Transfer Theory and Experiments with Liquid Metals, ORNL 361, Oak Ridge National Laboratory.

McGlaun, J. M., Thompson, S. L., Kmetyk, L. N., and Elrick, M. G., July 1990. A Brief Description of the Three-Dimensional Shock Wave Physics Code CTH, SAND89-0607, Sandia National Laboratories.

Siman-Tov, M., Wendel, M. W. and Haines, J. R., June 1, 1997. "Thermal-Hydraulic Analysis of the Mercury Target for the National Spallation Neutron Source," Proceedings of the 2nd Advanced Reactors Safety Conference (ARS ‘97), Orlando, Florida. 